\title{
DESIGUALDADES DE OPORTUNIDADES ENTRE JOVENS HOMENS E JOVENS MULHERES QUE NÃO ESTUDAM NEM ESTÃO OCUPADOS(AS) NO BRASIL
}

\author{
Luiz Carlos de Souza \\ UNIRIO \\ Eliane Ribeiro Andrade \\ UNIRIO
}

\begin{abstract}
Resumo
Estudos atuais da Organização Internacional do Trabalho, bem como do Instituto Brasileiro de Geografia e Estatística e do Instituto de Pesquisas Econômicas Aplicadas, entre outros, revelam o agravamento da situação dos jovens chamados de "nem-nem” (nem estudam nem trabalham). Dentre as razões desse agravamento estão as crises econômicas típicas do sistema capitalista, dificuldades dos jovens em se adequar às novas exigências de perfil pessoal e profissional impostas, e a falta ou ineficácia de políticas públicas voltadas para esse público. Tais estudos também revelam que entre os jovens mais afetados por essa condição, a maioria é de jovens mulheres, pobres, com baixa escolaridade e com acesso a uma educação precária. Nosso enfoque está nessas evidências que apontam, por exemplo, fortes desigualdades ligadas ao sexo dos jovens. Utilizamos dados fornecidos por jovens à pesquisa “Agenda Juventude Brasil” e realizamos análises estatísticas descritivas para evidenciar características do perfil daqueles que se enquadram na condição de "nem-nem”. Em seguida, investigamos o comportamento de um conjunto de variáveis realizando comparações com os achados de outros estudos no campo. Os resultados evidenciam semelhanças e diferenças em relação aos demais estudos analisados. Destacamos que na nossa pesquisa a condição "nem-nem” associa-se mais às mulheres de classe social mais baixa, não brancas, com vinte e dois anos ou mais, que concluíram o Ensino Médio, vivendo com parceiros(as) e com pelo menos um filho.
\end{abstract}

Palavras-chave: Políticas públicas de juventude; jovens nem-nem; juventude; educação e trabalho.

\begin{abstract}
Current studies by the International Labor Organization (ILO), as well as the Instituto Brasileiro de Geografia e Estatística (IBGE) and Instituto de Pesquisas Econômicas Aplicadas (IPEA), among others, reveal the worsening situation of young people called "NEET" (not in education, employment, or training). Among the reasons for this worsening are the economic crises typical of the capitalist system, the difficulties of young people to adapt to the new demands of personal and professional profile imposed, and the lack or inefficacy of public policies aimed at this public. These studies also reveal that among the young people most affected by this condition, the majority are young women, poor, with low schooling and with access to low quality education. Our focus is on these evidences that point, for example, to strong inequalities linked to the sex of young people. We used data provided by young people to the "Agenda Juventude Brasil" research and performed descriptive statistical analyzes to highlight characteristics of the profile of those who fall into the "NEET" condition. Then we investigate the behavior of a set of variables by making frequent comparisons with the findings of other studies in the field. Our results show similarities and differences in relation to the other studies analyzed. For example, in our research, the "NEET" condition is more associated with poor and non-white women, who are twenty-two years of age or older, who finished high school, living with partners and with at least one child.
\end{abstract}

ISSN 1645-1384 (online) www.curriculosemfronteiras.org

http://dx.doi.org/10.35786/1645-1384.v19.n3.21 
Keywords: NEET youth; youth; education and work.

O termo “nem-nem” refere-se, de modo geral, a indivíduos jovens que nem estão participando do mercado de trabalho, nem frequentam a educação formal. Essa categoria ganhou espaço no debate público brasileiro, como também no latino-americano, a partir da década de $2000^{1}$, influenciando, sobretudo, a formulação e execução de políticas públicas de juventude destinadas, no Brasil, a uma população total de cerca de 51,34 milhões de jovens entre 15 e 29 anos, compondo 26,8\% da população do país (IBGE, Censo 2010). No Brasil, diversas situações de fragilidade social estão associadas ao grupo de jovens que nem trabalham e nem estudam, e percepções que não levem em conta as peculiaridades características desse grupo quando da elaboração de modelos explicativos podem implicar na construção de cenários e ações públicas distantes de sua realidade social.

Dessa forma, o aprofundamento desse debate torna-se imperativo, na medida em que pode contribuir para qualificar dados sobre quem são esses jovens e o que significa inatividade de jovens para diferentes sujeitos. Pesquisas recentes têm apontado que, embora o número de jovens qualificados como nem-nem seja bastante expressivo, a duração média nessa condição é curta, com indícios de grande rotatividade dos jovens em relação ao mercado de trabalho, indicando fortemente que, na maioria dos casos, a situação é transitória (Menezes Filho, Cabanas e Komatsu, 2013). Outro dado relevante, que inspira este artigo, é a constatação de que a maioria dos jovens brasileiros, na situação de nem-nem é composta por mulheres.

Na média da OCDE, por exemplo, em 2015, enquanto $14,8 \%$ do total de jovens homens entre 15 e 29 anos foram identificados como "nem-nem” o percentual subia para 17,4\% entre as mulheres. No Brasil, no entanto, a situação se mostrava muito mais grave, já que o percentual para os homens era de 22,5\% e 29,8\% entre as mulheres, expressando, portanto proporções superiores à média da OCDE, além de uma desigualdade mais expressiva entre homens e mulheres. Assim, as informações evidenciam o peso determinante das jovens mulheres no elevado índice de “nem-nem” encontrado no Brasil.

O cenário exposto acima pode ser explicado por um conjunto de fatores econômicos, políticos, sociais e culturais, os quais variam de nação para nação, mas que também, por vezes, constituem-se em pontos em comum entre alguns países. Nesse sentido, De Hoyos, Rogers e Székely (2016) analisaram dados de pesquisas realizadas entre 1992 e 2010, em diversos países da América Latina, para traçar um perfil dos jovens de 15 a 24 anos que se encaixavam na condição de “nem-nem”. Segundo esses autores, dentre aproximadamente 92,2 milhões de jovens entre 15 a 24 anos da América Latina em 2010, um pouco mais que 18 milhões não estavam na escola nem trabalhavam, mas asseguravam que por uma série de questões ligadas à ambrangência e metodologia da pesquisa, tanto como pelo efetivo aumento da população jovem, esse número chegava a 20,8 milhões no ano de 2015.

Ainda segundo os autores, as proporções de jovens "nem-nem” variam muito entre os países da América Latina, mas apresentam alguns traços comuns. Dentre eles, o de que os “nem-nem” eram majoritariamente de zonas rurais e tinham baixo nível de escolaridade 
(mais de 25\% sem ensino primário completo e outros 43\% que haviam completado o primário, mas não o secundário). Uma semelhança que destacamos é a de que os dados reforçam que, quase sem exceções, as mulheres normalmente estão muito mais sujeitas a esta situação do que os homens. Já que dos 18 milhões de jovens “nem-nem” apontados em 2010, 12 milhões (66,6\%) eram mulheres. Dois terços delas ainda moravam com os pais e não procuravam trabalho. As restantes formaram uma nova família e já tinham crianças e, na maioria dos casos, não procuravam emprego. Essas descobertas são corroboradas por uma série de outras investigações (JACINTO, 2016; OCDE/CEPAL/CAF, 2016; OCDE, 2017; FEIJOÓ, 2015). Nesse sentido, e Feijoó (2015) identifica um agravante, afirmando que em países da América Central a proporção de mulheres que nem estudam nem trabalham é três vezes maior que a de homens.

No Brasil, Castro (2004) baseou-se em dados da Pesquisa Nacional por Amostra de Domicílios (PNAD) do IBGE para afirmar a existência de uma equação perversa na relação entre trabalho e estudo quando se considera a população de jovens de 15 a 24 anos apontando também que

(...) a maior proporção de jovens que não estuda nem trabalha, assim como a que só estuda é do sexo feminino. A maioria dos jovens rapazes que não estudam e não trabalham, segundo a PNAD 2001, estaria na situação de filhos (80,4\%), enquanto ao se considerar as jovens mulheres que também não estudam e não trabalham tem-se que $42,6 \%$ estariam na situação de cônjuges e 41,1\% como filhas. Portanto gênero empresta singularidades a equação trabalho e estudo no caso dos jovens, o que deve ser matéria de políticas especificas. (CASTRO, 2004, pág. 292293)

Nessa linha, Monteiro (2013) produz uma série histórica com base nas PNAD de 2001 a 2011 revelando que jovens considerados “nem-nem” na faixa etária de 19 e 24 anos eram, majoritariamente, mulheres, totalizando 75\% dos jovens nessa situação em 2011. A mesma autora ressalta também que a maternidade está significativamente associada à condição “nem-nem”, já que 45\% desses jovens eram mulheres com filhos. Tal evidência é corroborada por Marina Aguas, da Coordenação de Trabalho e Rendimento do Instituto Brasileiro de Geografia e Estatística (IBGE) ${ }^{2}$ e pode ser observada na figura 1, que revela que as jovens mulheres são a maioria absoluta entre os "nem-nem” ao longo de toda a série histórica analisada.

\section{Figura 1}




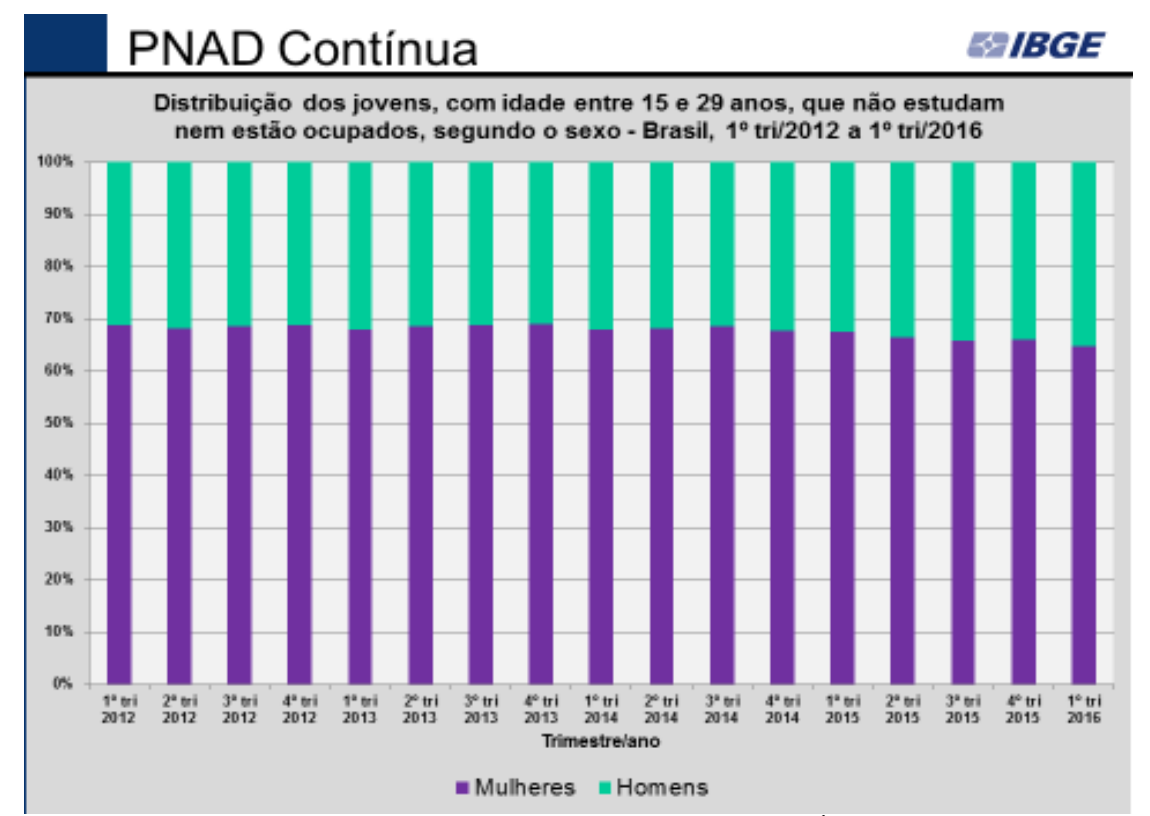

Fonte: IBGE/PNAD - 2016. Apresentação de Marina Águas, no Seminário sobre Juventude IBGE/IPEA, RJ, 2016.

Outros dados revelaram que, em nossa sociedade, a divisão de funções entre homens e mulheres coloca frequentemente estas últimas em tarefas ligadas à reprodução e ao cuidado com o lar e a educação das crianças. Nesse sentido, Souza e Guedes (2016) com base nas Pnads 2004 e 2014, investigam a divisão sexual do trabalho no Brasil e entre suas regiões no tocante à participação e horas dedicadas ao mercado de trabalho, bem como à participação e as horas dedicadas às tarefas domésticas. Os autores concluem que a divisão sexual do trabalho é desigual e desfavorável para as mulheres brasileiras de forma relativamente homogênea entre as regiões do país. Os dados da Coordenação de Trabalho e Rendimento do Instituto Brasileiro de Geografia e Estatística (IBGE) corroboram tais conclusões, mostrando que a proporção de mulheres que não trabalham por cuidar de pessoas ou tarefas domésticas é muito superior à de jovens homens, conforme expresso nas faixas amarelas das figuras 2 e 3 , a seguir.

Figura 2 


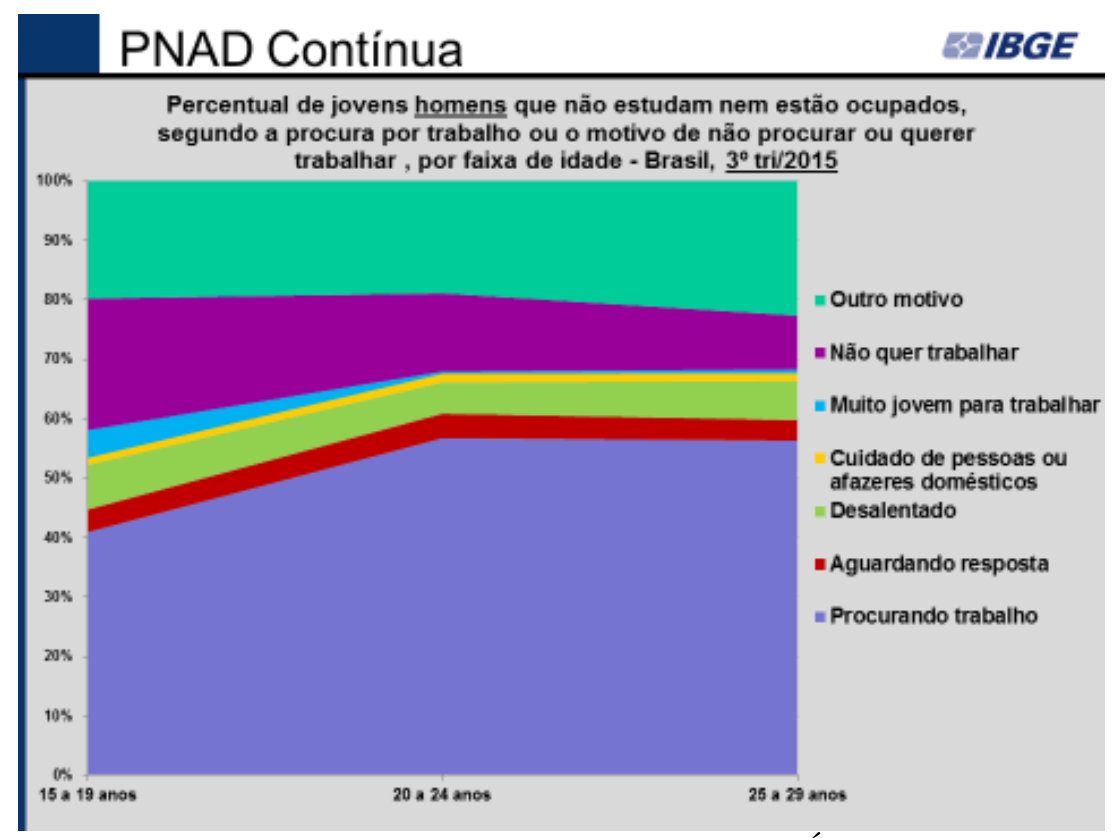

Fonte: IBGE/PNAD - 2016. Apresentação de Marina Águas, no Seminário sobre Juventude IBGE/IPEA, RJ, 2016.

Figura 3

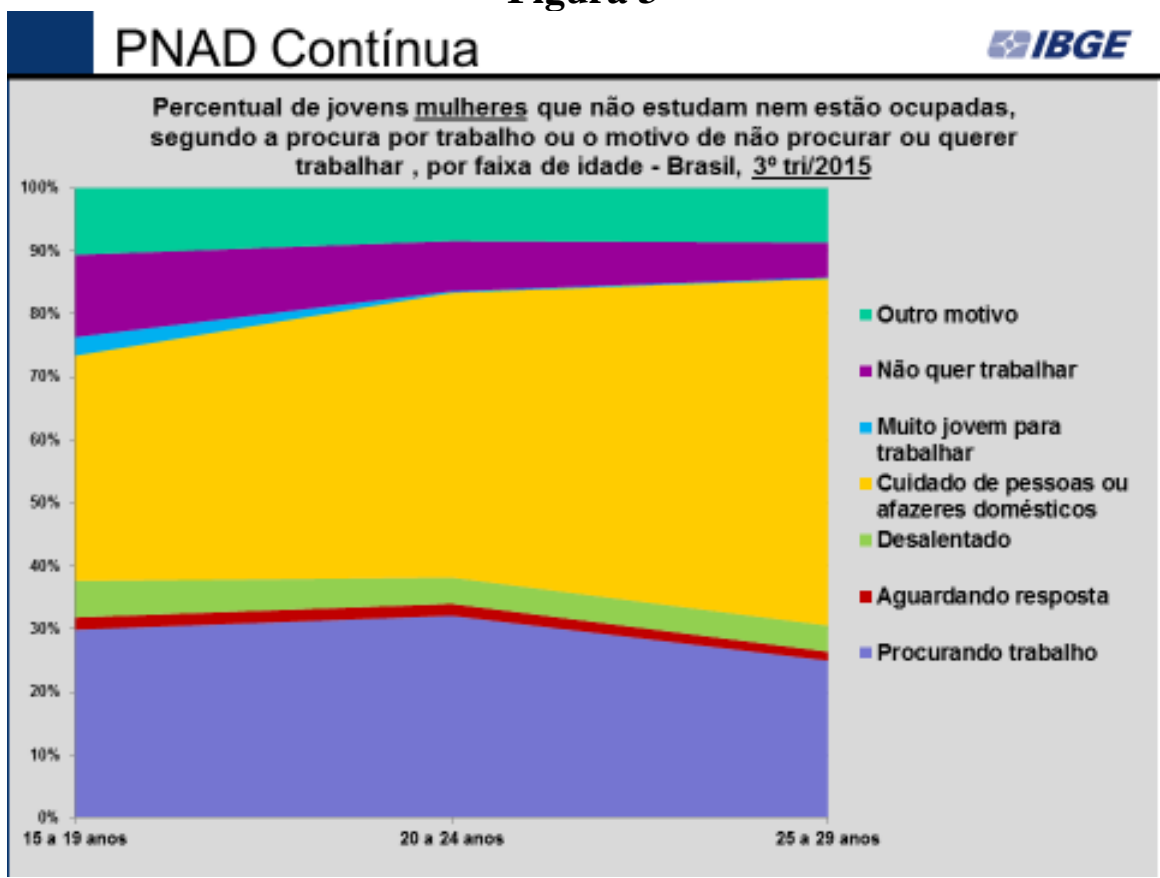

Fonte: IBGE/PNAD - 2016. Apresentação de Marina Águas, no Seminário sobre Juventude IBGE/IPEA, RJ, 2016. 
Os dados levantados até aqui evidenciam que vários fatores estão ligados à condição juvenil de "nem-nem” em diversos países do mundo. Dentre estes fatores, ainda que se leve em conta as singularidades expressas por cada país ou grupo de países, parece haver alguns que são comuns entre nações e mesmo entre continentes diferentes (como o aumento do número de jovens "nem-nem” nos últimos anos, as desigualdades regionais e estigmas de vadiagem e violência associados à essa condição). Contudo, o fator que destacamos é o que se refere à desvantagem em que se encontram as jovens mulheres nesse contexto. Essa desvantagem não é casual, mas sim resultante de uma construção histórica e cultural em que se entrelaçam a representação sociocultural das mulheres e a divisão de papéis sociais desiguais que estas vêm sendo levadas a cumprir em estruturas que oferecem, de forma desigual, o reconhecimento, as valorizações e tratamentos dados a homens e mulheres resultando, muitas vezes, em distribuições desiguais de tratamento, oportunidades, direitos e deveres.

Seguindo essa linha, Arruda (2002) afirma que o status atribuído às mulheres em nossa sociedade é fortemente marcado por sua condição social e biológica. Essa condição, por sua vez, afeta suas ideias, práticas e experiências bem como os processos pelos quais tais ideias, práticas e experiências são geradas e compreendidas. A autora argumenta que essa condição feminina não é somente diferenciada, mas desigual, afirmando que o ponto de vista feminino foi histórica e culturalmente assimilado em estruturas de hierarquização de valores existentes em nossas culturas, resultando na inferiorização das ideias, práticas e experiências das mulheres.

Em corroboração a estes argumentos, Castro (2004) defende que a juventude é um ciclo decisivo para demarcação de diferenças no campo de identidades que podem tanto potencializar criatividades e singularidades como favorecer a produção de divisões sexuais assimétricas, desiguais entre os jovens.

Estes entendimentos, que remetem a desigualdades que pesam sobre as mulheres em diversas dimensões da vida social, nos permitem compreender alguns dos elementos que as colocam, forçosamente, num lugar de maioria entre os “nem-nem". Assim, é no sentido de reiterar, mas também de fornecer novos dados e contribuir para o aprofundamento da compreensão sobre as juventudes “nem-nem” que apresentamos a análise que se segue, com base nos dados da pesquisa Agenda Juventude Brasil.

\section{Agenda Juventude Brasil: perfil e inatividade}

Nossos dados são oriundos da Pesquisa Nacional Agenda Juventude Brasil - Perfil e Opinião dos Jovens Brasileiros, de 2013, coordenada pela Secretaria Nacional de Juventude. O survey foi representativo da população brasileira de 15 a 29 anos de idade, e baseado numa amostra aleatória, de 3.300 entrevistas, estratificada em múltiplos estágios. A pesquisa foi realizada com um intervalo de confiança de $95 \%$ e margem de erro para o total da amostra de 2 pontos percentuais para mais ou para menos. Participaram 187 
municípios, estratificados segundo sua localização geográfica, se capital, região metropolitana ou interior, localidade urbana ou rural, porte demográfico pequeno, médio ou grande e tercis da população. ${ }^{3}$

Para nossa análise, inicialmente selecionamos apenas os jovens na condição de "nemNem” naquela ocasião. Chegamos ao total de 763 respondentes, os quais representam 23,3\% dos das respostas válidas.

\section{Perfil dos jovens nem-nem por sexo}

Um primeiro dado verificado, conforme exposto no gráfico 1, é que mais de dois terços dos jovens "nem-nem" é de mulheres (69,3\%). Chama a atenção a diferença entre a maioria de mulheres e a minoria de homens nessa situação já que a diferença é de 38,6 pontos percentuais indicando que essa condição está fortemente associada ao sexo dos jovens.

Gráfico 1 - Distribuição dos jovens por sexo

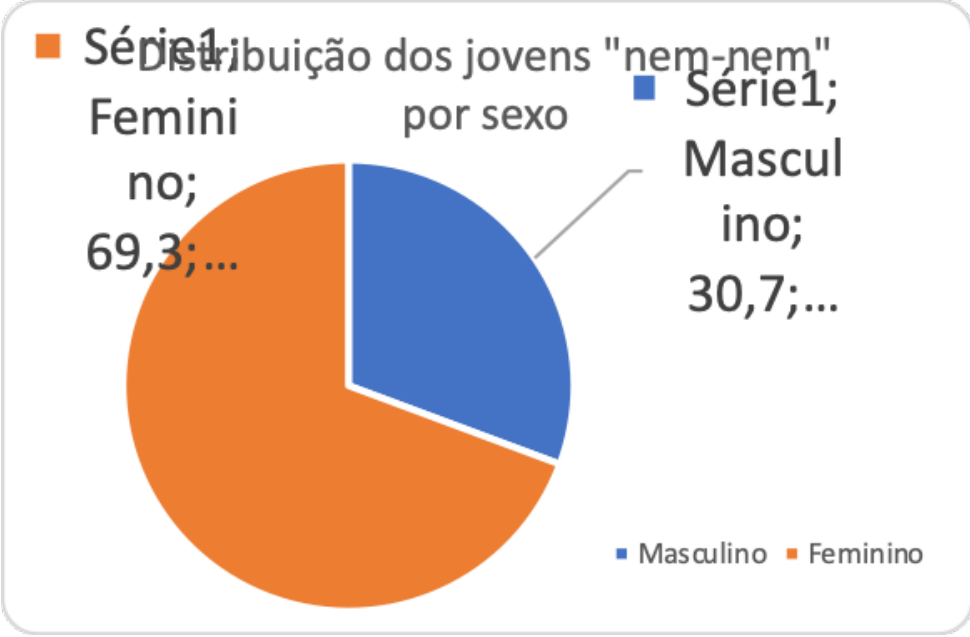

Fonte: Elaboração própria, a partir dos dados da pesquisa Agenda Juventude Brasil, 2013.

Há uma distribuição heterogênea dos jovens pelas faixas etárias, conforme se pode observar no gráfico 2. No entanto, as mulheres "nem-nem” têm idade ligeiramente mais avançada que os homens, já que aquelas na faixa de 22 a 25 anos são maioria (33,8\%), seguidas daquelas com idades entre 26 e 29 anos (30,2\%). Note-se ainda o agravante de que há, por um lado, 9,8\% de jovens homens e 6,4\% de jovens mulheres em idade de escolaridade obrigatória.

Gráfico 2 - Faixa etária dos jovens “nem-nem” por sexo 


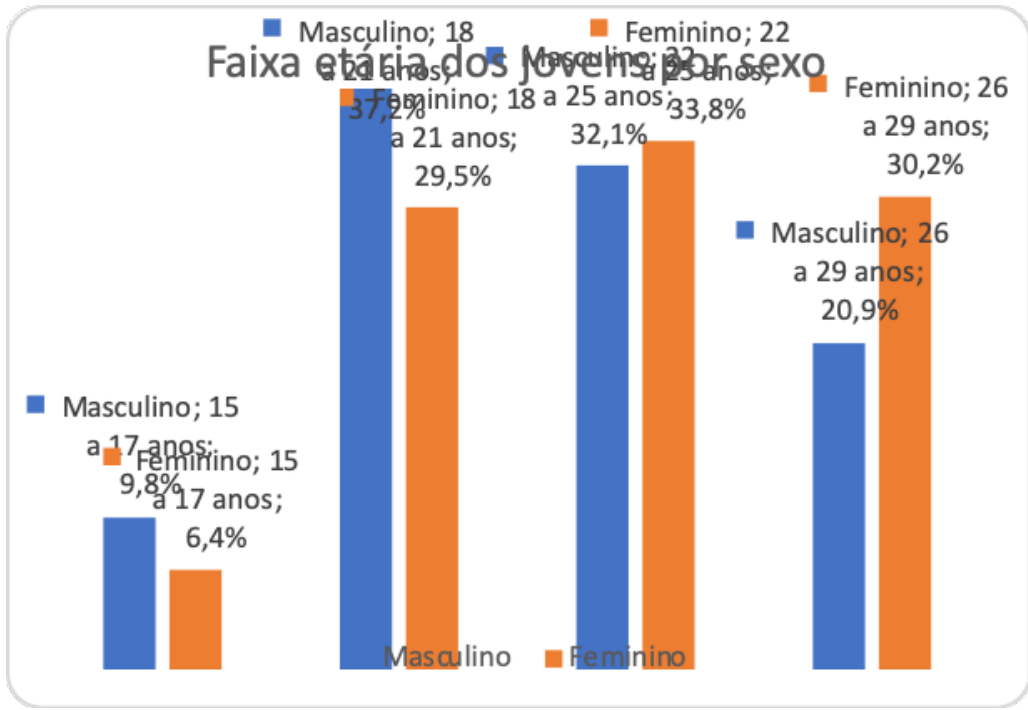

Fonte: Elaboração própria, a partir dos dados da pesquisa Agenda Juventude Brasil, 2013.

Segundo a pesquisa as características étnico-raciais, representam um fator de similitude entre homens e mulheres quando analisamos a condição de "nem-nem". Conforme observado no gráfico 3, entre os "nem-nem”, as diferenças percentuais entre homens e mulheres são sempre pequenas, independentemente da classificação de cor/raça. Contudo, os dados revelam a existência de uma desigualdade que corrobora resultados de outras pesquisas que versam sobre as relações entre sexo e/ou de raça com desigualdades de oportunidades educacionais e laborais no Brasil (HENRIQUES 2002; ABRAMO, 2006; IPEA, 2011; DIAS E VASCONCELOS, 2016 ).

Dados do Censo demográfico de 2010, do IBGE mostram, como se pode observar na tabela 1, que entre a população de 15 a 29 anos no Brasil, a maioria é composta por pardos $(46,2 \%)$ e brancos $(44,4 \%)$ enquanto os que se declaram pretos totalizam $7,8 \%$.

Tabela 1 - Distribuição da população jovem de 15 a 29 anos no Brasil por cor/raça

\begin{tabular}{r|r|r|r|r|r}
\hline \multicolumn{1}{c|}{ Branca } & \multicolumn{1}{c|}{ Preta } & Amarela & \multicolumn{1}{c}{ Parda } & \multicolumn{1}{c}{ Indígena } & \multicolumn{1}{c}{ Total } \\
\hline 30.334 .071 & 5.353 .863 & 756.809 & 31.580 .141 & 303.491 & 68.331 .350 \\
\hline $44,4 \%$ & $7,8 \%$ & $1,1 \%$ & $46,2 \%$ & $0,4 \%$ & $100,0 \%$ \\
\hline
\end{tabular}

Fonte: IBGE - Censo demográfico - 2010

Estes percentuais modificam-se quando tratamos da juventude "nem-nem” e evidenciam que a presença de jovens brancos é expressivamente menor que aquela apontada em nível nacional, já que passa de 44,4\% no total para $29 \%$ entre as mulheres e 
$25 \%$ entre os homens. Ao mesmo tempo, o percentual de pardos sofre um pequeno acréscimo, mas o de pretos mais do que dobra, passando dos $8 \%$ da população total para $18 \%$ entre os "nem-nem". Nesse caso, não seria equivocado afirmar que há uma sobreposição de desigualdades que afetam jovens mulheres, sobretudo quando estas não são brancas.

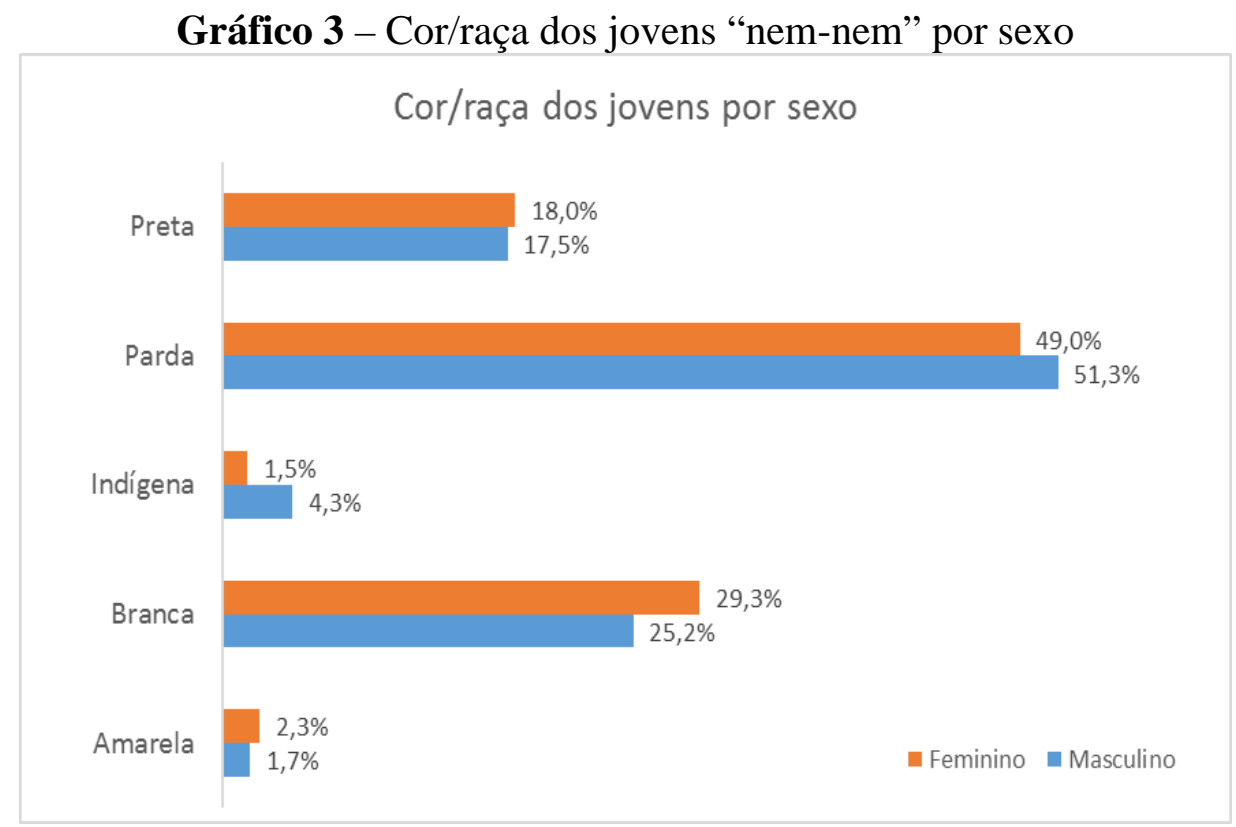

Fonte: Elaboração própria, a partir dos dados da pesquisa Agenda Juventude Brasil, 2013.

Em relação ao estado conjugal dos jovens “nem-nem” a tabela 2 mostra que a grande maioria dos homens $(76,1 \%)$ é composta por solteiros. O percentual dos que moram com parceiros/as (16,2\%), bem como os casados no civil $(5,6 \%)$ são, por sua vez, muito menores. A situação se inverte, contudo, entre as mulheres "nem-nem”, já que as solteiras, nesse caso, são minoria (42\%) enquanto, somadas, as que moram com parceiro/a $(33,3 \%)$ e as casadas no civil (20,4\%) são 53,6\%.

Tabela 2 - Estado conjugal dos jovens “nem-nem” por sexo 


\begin{tabular}{|c|c|c|c|c|c|}
\hline Sexo & Estado conjugal & $\%$ & Sexo & Estado conjugal & $\%$ \\
\hline \multirow{6}{*}{ Masculino } & Casado/a no civil & $5,6 \%$ & \multirow{6}{*}{ Feminino } & Casado/a no civil & $20,4 \%$ \\
\hline & Mora com parceiro/a & $16,2 \%$ & & Mora com parceiro/a & $33,3 \%$ \\
\hline & Separado/a & $2,1 \%$ & & Separado/a & $3,0 \%$ \\
\hline & Solteiro/a & $76,1 \%$ & & Solteiro/a & $42,0 \%$ \\
\hline & Viúvo/a & $0,0 \%$ & & Viúvo/a & $1,1 \%$ \\
\hline & Total & $100,0 \%$ & & Total & $100,0 \%$ \\
\hline
\end{tabular}

Fonte: Elaboração própria, a partir dos dados da pesquisa Agenda Juventude Brasil, 2013.

Em relação à posse de filhos, percebe-se que também há diferenciações consideráveis entre homens e mulheres. De acordo com o gráfico 4, entre os homens, são 75,0\% os que não têm filhos. A situação se inverte ao observamos as mulheres, já que a grande maioria (67,5\%) tem filhos.

Gráfico 4 - Posse de filhos dos jovens “nem-nem” por sexo

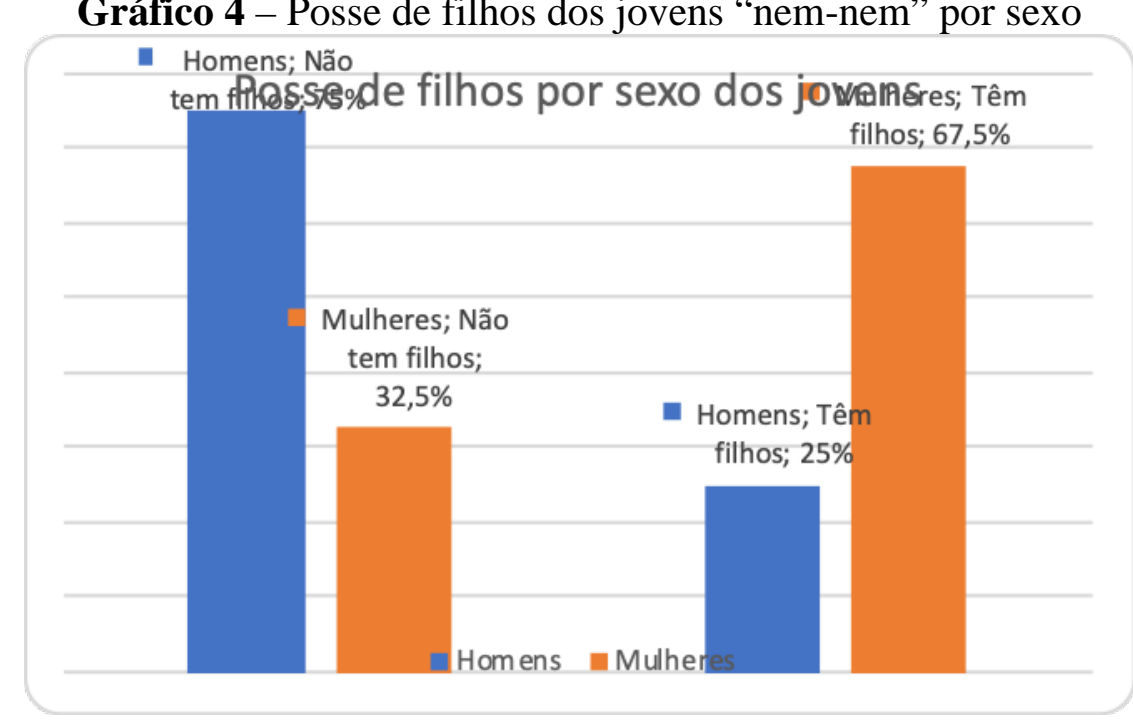

Fonte: Elaboração própria, a partir dos dados da pesquisa Agenda Juventude Brasil, 2013.

Destaca-se ainda, como exposto na tabela 3, que entre os homens que têm filhos, a maioria possui apenas um. Ao contrário, no caso das mulheres com filhos, a proporção das que têm dois filhos ou mais se equipara àquela das que possuem apenas um filho.

Tabela 3 - Número de filhos por sexo e condição de trabalho e estudo 


\begin{tabular}{|c|c|c|c|c|c|}
\hline Sexo & $\mathrm{N}^{\mathrm{o}}$ de filhos & Proporção & Sexo & $\mathrm{N}^{\mathrm{o}}$ de filhos & Proporção \\
\hline \multirow{8}{*}{ Masculino } & Um filho & $17,9 \%$ & \multirow{8}{*}{ Feminino } & Um filho & $33,7 \%$ \\
\hline & Dois filhos & $3,8 \%$ & & Dois filhos & $23,1 \%$ \\
\hline & Três filhos & $1,9 \%$ & & Três filhos & $6,9 \%$ \\
\hline & Quatro filhos & $0,9 \%$ & & \begin{tabular}{|l|} 
Quatro filhos \\
\end{tabular} & $3,2 \%$ \\
\hline & Cinco filhos & $0,5 \%$ & & Cinco filhos & $0,6 \%$ \\
\hline & Oito filhos & $0,0 \%$ & & Oito filhos & $0,0 \%$ \\
\hline & Não tem filhos & $75,0 \%$ & & Não tem filhos & $32,5 \%$ \\
\hline & Total & $100,0 \%$ & & Total & $100,0 \%$ \\
\hline
\end{tabular}

Fonte: Elaboração própria, a partir dos dados da pesquisa Agenda Juventude Brasil, 2013.

Em relação a qual classe econômica consideram pertencer, tanto os homens quanto as mulheres "nem-nem" concentram-se nas classes econômicas mais baixas. A tabela 4 evidencia que os percentuais mais elevados entre os homens são os da classe média-baixa, alcançando os 48,5\%. Outros 33,5\% deles se vê como de classe média-média enquanto $14,6 \%$ se percebem como pobres e $1,3 \%$ como muito pobres.

No caso das mulheres, mesmo que o percentual das de classe média-baixa se equipare ao dos homens (48,5\%), há $18,2 \%$ que se consideram pobres e $1,5 \%$ que se consideram muito pobres. O percentual das que se vêem como de classe média-média é de 27,7\% (menor que o dos homens), enquanto as de classe média-alta, que totalizam 3,8\%, são discretamente mais frequentes que os homens (2,1\%). Para ambos, praticamente inexistem percepções de serem ricos ou muito ricos.

Tabela 4 - Classe econômica à qual disse pertencer, por sexo

\begin{tabular}{|c|c|c|c|c|c|}
\hline Sexo & Classe & Proporção & Sexo & Classe & Proporção \\
\hline \multirow{8}{*}{ Masculino } & Muito pobre & $1,3 \%$ & \multirow{8}{*}{ Feminino } & Muito pobre & $1,5 \%$ \\
\hline & Pobre & $14,6 \%$ & & Pobre & $18,2 \%$ \\
\hline & Média-baixa & $48,5 \%$ & & Média-baixa & $48,5 \%$ \\
\hline & Média-média & $33,5 \%$ & & Média-média & $27,7 \%$ \\
\hline & Média-alta & $2,1 \%$ & & Média-alta & $3,8 \%$ \\
\hline & Rica & $0,0 \%$ & & Rica & $0,0 \%$ \\
\hline & Muito rica & $0,0 \%$ & & Muito rica & $0,4 \%$ \\
\hline & Total & $100,0 \%$ & & Total & $100,0 \%$ \\
\hline
\end{tabular}

Fonte: Elaboração própria, a partir dos dados da pesquisa Agenda Juventude Brasil, 2013.

Os dados sobre a renda familiar dos jovens confirmam sua percepção sobre a classe econômica em que se percebem, mostrando que tanto os jovens quanto as jovens "nemnem” concentram-se mais nas rendas familiares mais baixas. Contudo, as desigualdades continuam se revelando. Enquanto 51,7\% dos homens têm renda familiar de até dois salários mínimos, esse é de 66,8\% entre as mulheres. Já o percentual dos homens com 
renda familiar de mais de quatro até dez salários mínimos é de 10,2\%, enquanto entre as mulheres o percentual é de 5,2\%.

No tocando à escolaridade, como exposto na tabela 5, tanto entre os homens quanto entre as mulheres, a maioria afirma ter conseguido chegar ao Ensino Médio regular ou técnico. É claro que não se pode desconsiderar que entre os jovens do sexo masculino há $38,5 \%$ que deixaram a escola sem chegar ao Ensino Médio. Contudo o percentual dos que chegaram é de 58,1\%.

As mulheres, de forma geral, encontram-se em situação discretamente melhor que os homens nesse caso e nossos dados corroboram dados oficiais que mostram que as mulheres vêm alcançando níveis mais altos de escolaridade em relação aos homens, ainda que a estrutura ocupacional de homens e mulheres permaneça muito desigual (IBGE, 2014 e 2018). Entre elas, 61,8\% chegaram ao Ensino Médio, mesmo não podendo desprezar o expressivo percentual, de 33,3\% que, assim como os homens, deixou os estudos antes do Ensino Médio. Por fim, percebemos distinções sutis entre homens e mulheres ao analisarmos os percentuais dos que chegaram ao Ensino Superior, ainda assim, com as mulheres em relativa vantagem.

Tabela 5 - Escolaridade dos jovens por sexo

\begin{tabular}{|c|c|c|c|c|c|}
\hline Sexo & Escolaridade & $\%$ & Sexo & Escolaridade & $\%$ \\
\hline \multirow{6}{*}{ Masc. } & Não frequentou escola & $0,9 \%$ & \multirow{6}{*}{ Fem. } & Não frequentou escola & $0,0 \%$ \\
\hline & Ensino Fundamental & $38,5 \%$ & & Ensino Fundamental & $33,3 \%$ \\
\hline & Ensino Médio ou técnico & $58,1 \%$ & & Ensino Médio ou técnico & $61,8 \%$ \\
\hline & Superior & $2,6 \%$ & & Superior & $4,5 \%$ \\
\hline & Pós-Graduação & $0,0 \%$ & & Pós-Graduação & ,4\% \\
\hline & Total & $100,0 \%$ & & Total & $100,0 \%$ \\
\hline
\end{tabular}

Fonte: Elaboração própria, a partir dos dados da pesquisa Agenda Juventude Brasil, 2013.

Os jovens responderam sobre sua situação em relação ao trabalho. A tabela 6 mostra que 62,0\% dos jovens homens já trabalhou e estava à procura de trabalho. Contudo, o percentual das jovens mulheres que se encontravam na mesma condição era de apenas $36,2 \%$, valor pouco superior aos 35,0\% também de mulheres que já trabalharam, mas não estavam procurando trabalho. Já a proporção de 19,1\% mulheres que nunca trabalhou e nem procurava trabalho remunerado é bem superior aos 10,3\% de homens que deram a mesma resposta. 
Tabela 6 - Situação dos jovens que não trabalham nem estudam em relação ao trabalho, por sexo

\begin{tabular}{l|r|r}
\hline \multirow{2}{*}{\multicolumn{1}{c|}{ Situação }} & \multicolumn{2}{c}{ Sexo } \\
\cline { 2 - 3 } & Masc. & \multicolumn{1}{c}{ Fem. } \\
\hline Nunca fez nenhum trabalho remunerado e não está procurando trabalho & $10,3 \%$ & $19,1 \%$ \\
\hline Nunca trabalhou, mas está procurando trabalho & $9,0 \%$ & $9,7 \%$ \\
\hline Já trabalhou e está procurando trabalho & $62,0 \%$ & $36,2 \%$ \\
\hline Já trabalhou, mas não está procurando trabalho & $18,8 \%$ & $35,0 \%$ \\
\hline Total & $100,0 \%$ & $100,0 \%$ \\
\hline
\end{tabular}

Fonte: Elaboração própria, a partir dos dados da pesquisa Agenda Juventude Brasil, 2013.

\section{Considerações finais}

Os dados oriundos da pesquisa Agenda Juventude Brasil, evidenciam um cenário em que as jovens mulheres encontram-se em desvantagem em relação aos jovens homens em uma condição já desfavorável para ambos os sexos. Ao mesmo tempo, tais dados corroboram os registros de outros investigadores do campo, bem como dados oficiais internacionais e nacionais, ressaltando que, no caso brasileiro, as desigualdades entre os jovens homens e jovens mulheres designados como "nem-nem" encontram-se entre as mais gritantes.

De início, fica evidente que os jovens “nem-nem”, tanto homens quanto mulheres, são pessoas de nível socioeconômico baixo, com rendas familiares de até dois salários mínimos, mas a proporção de mulheres nesse extrato é muito maior que a de homens. Assim, evidencia-se que há desigualdades resultantes da distribuição sócio-sexual de papéis e nossos dados revelam que muito mais mulheres na condição de nem-nem são casadas e possuem filhos (em maior quantidade do que os homens), o que pode ajudar a explicar a razão pela qual as mulheres, muito mais do que os homens, não trabalham por estar cuidando de pessoas ou de afazeres domésticos.

Foi possível observar também que a maioria dos jovens "nem-nem", independentemente do sexo, concluiu o ensino médio ou técnico. No entanto, mesmo tendo, em média, idades mais avançadas, mas, sobretudo, níveis de escolaridade discretamente mais elevados que os homens, uma proporção muito menor das mulheres "nem-nem", já haviam trabalhado e estavam à procura de trabalho. Por outro lado, também se comparando aos homens, uma proporção maior de mulheres nunca trabalhou e nem procurava trabalho remunerado. Mais uma vez, nossa hipótese explicativa volta-se para a distribuição de papéis sociais e pode ter relação com os argumentos já citados acerca da relação conjugal, da posse de filhos e do cuidado de pessoas e do lar. O peso desses fatores, por sua vez remete ao patriarcalismo arraigado em nossa cultura no âmbito do qual, como afirma Nogueira (2010, pág. 59) “(...) o marido se mantém provedor e a esposa a provedora complementar e dona de casa, confirmando a divisão sexual desigual do trabalho". Esse 
cenário, que se configura, para a mesma autora, como uma divisão “sociosexual” do trabalho, revela uma hierarquia que influencia fortemente “(...) na desqualificação do trabalho feminino assalariado, no sentido da desvalorização da força de trabalho $e$ conseqüentemente desencadeando uma acentuada precarização feminina no mundo produtivo".

Outra evidência que ressalta uma faceta perversa de nossa cultura é a que se refere às desigualdades de matriz étnico-racial. Conforme expusemos, a população preta de jovens homens e jovens mulheres brasileiros é a mais prejudicada quando se compara sua proporção na composição demográfica geral do país com sua presença entre os "nem-nem”. Ressalta-se ainda que também há aumentos, ainda que discretos, das proporções de indivíduos enquadrados em todas as classificações de cor-raça entre os "nem-nem”, com exceção da população branca, onde se percebe uma grande redução.

A pesquisa “Agenda Juventude Brasil” traz também outros dados que se traduzem em fatores ligados à miríade de desigualdades que caracteriza a cultura brasileira e que não incluímos aqui devido à ênfase que optamos por dar aos temas que tratamos. É inegável (e uma infinidade de pesquisas e dados oficiais comprovam isso) que a região do país onde vivem, a localização urbana ou rural, o porte do município em que residem, as opções locais de educação e trabalho, entre outros fatores, podem agravar ainda mais o cenário para os jovens "nem-nem”. Lembremos que cada cidadão em nosso país está sempre associado a uma combinação de todas estas variáveis que, em seu conjunto, podem colocálo em situação favorável ou desfavorável. É crucial a elaboração e execução de políticas públicas de combate ao crescimento do número de jovens “nem-nem”, mas também indispensável à identificação e o ataque aos fatores do perfil desses jovens que os colocam em tamanha desvantagem em relação aos demais.

\section{Notas}

${ }^{1} \mathrm{O}$ termo foi registrado, pela primeira vez, na década de noventa no Reino Unido, e passou a ser amplamente utilizado por organismos ligados à comunidade européia para o monitoramento de vulnerabilidades da juventude (Feijoó, 2015).

${ }^{2}$ Apresentação realizada no Seminário: Juventude IBGE/IPEA. Rio de Janeiro, julho de 2016,

${ }^{3}$ Venturi e Riscal (2016) “Agenda juventude Brasil: notas metodológicas sobre a amostra e o tratamento dos resultados. In: Pinheiro [et al]. Agenda Juventude Brasil: Leituras sobre uma década de mudanças. Rio de Janeiro, UNIRIO, 2016. Disponível em: http://polis.org.br/publicacoes/10759-2/

\section{Referências}

ABRAMO, L. Desigualdades de gênero e raça no mercado de trabalho brasileiro. Ciência e Cultura, São Paulo, v. 58, n. 4, p. 40-41, out./dez. 2006.

ARRUDA, Â. Teoria das representações sociais e teorias de gênero. Cadernos de Pesquisa, n. 117, p. 127-147, novembro/ 2002. 
BRASIL. SECRETARIA NACIONAL DE JUVENTUDE. Agenda Juventude Brasil: pesquisa Nacional sobre Perfil e Opinião dos Jovens Brasileiros 2013. Brasília: SNJ, 2014.

CASTRO, M. G. Políticas públicas por identidades e de ações afirmativas: acessando gênero e raça, na classe, focalizando juventudes. In: NOVAES, Regina; VANNUCHI, Paulo. Juventude e sociedade: trabalho, educação, cultura e participação. São Paulo: Fundação Perseu Abramo, 2004. p. 275-303.

DE HOYOS, R.; ROGERS, H.; SZÉKELY, M. Ninis en América Latina: 20 millones de jóvenes em busca de oportunidades. Banco Mundial, Washington, DC. Licencia: Creative Commons de Reconocimiento CC BY 3.0 IGO, 2016.

DIAS, T. S.; VASCONCELOS, A. M. N. Juventudes em transição no contexto do bônus demográfico: a inserção social dos/das jovens que não trabalham nem estudam. XX ABEP: Anais do XX Encontro Nacional de Estudos Populacionais, 2016. Disponível em: http://www.abep.org.br/ abeporgb/publicacoes/index.php/anais/article/view/2904/2770

FEIJOÓ, M. C. Los ni-ni: una visión mitológica de los jóvenes latinoamericanos. In: Tendencias en Foco, No30 - Marzo/2015. RedEtis-IIPE-UNESCO.

HENRIQUES, R. Raça e gênero no sistema de ensino: os limites das políticas universalistas na educação / Ricardo Henriques. - Brasília: UNESCO, 2002. 100p.

IBGE. Síntese de indicadores sociais: Uma análise das condições de vida da população brasileira. Estudos e pesquisas: Informação demográfica e socioeconômica n.36, 2016. Disponível em: http://biblioteca.ibge.gov.br/biblioteca-catalogo?view=detalhes\&id=295011

Estatísticas de Gênero: Uma análise dos resultados do Censo Demográfico de 2010. Estudos \& pesquisas: Informação demográfica e socioeconômica, $n^{0} 33$, Rio de Janeiro, 2014. Disponível em: https://biblioteca.ibge.gov.br/visualizacao/livros/liv88941.pdf

Estatísticas de Gênero: Indicadores sociais das mulheres no Brasil. Estudos \& pesquisas: Informação demográfica e socioeconômica, $n^{0}$ 33, Rio de Janeiro, 2018. Disponível

em: https://biblioteca.ibge.gov.br/visualizacao/livros/liv101551_informativo.pdf

IPEA. Retrato das desigualdades de gênero e raça. 4ª ed. - Brasília: IPEA, 2011. 39 p. il. JACINTO, C. Debates latino-americanos sobre los NINI. 2016 (paper).

MONTEIRO, J. Quem são os jovens nem-nem? Uma análise sobre os jovens que não estudam e não participam do mercado de trabalho. Fundação Getúlio Vargas. IBRE - textos para discussão: Texto de discussão $\mathrm{n}^{\circ}$ 34, setembro de 2013. 
NOGUEIRA, C. M. As relações sociais de gênero no trabalho e na reprodução. Revista Aurora, v. 3, n. 2, 2010.

OCDE/CEPAL/CAF (2016), Perspectivas económicas de América Latina 2017: Juventud, competencias y emprendimiento, OECD Publishing, Paris. http://dx.doi.org/10.1787/leo-2017-es

OECD (2017), Youth not in employment, education or training (NEET) (indicator). doi: 10.1787/72d1033a-en. Disponível em: https://data.oecd.org/youthinac/youth-not-inemployment-education-or-training-neet.htm

PINHEIRO, D.; RIBEIRO, E.; VENTURI, G.; NOVAES, R. Agenda Juventude Brasil: leituras sobre uma década de mudanças. Rio de Janeiro: UNIRIO, 2016.

SOUSA, L. P.; GUEDES, D. R.. A desigual divisão sexual do trabalho: um olhar sobre a última década. Estudos avançados, São Paulo , v. 30, n. 87, p. 123-139, Aug. 2016 . Disponível em <http://www.scielo.br/scielo.php?script=sci_arttext\&pid=S0103$40142016000200123 \& \operatorname{lng}=\mathrm{en} \& n r m=$ iso $>$.

\section{Correspondência}

Luiz Carlos de Souza: Professor da Universidade Federal do Estado do Rio de Janeiro - UNIRIO

E-mail: luiz.souza@unirio.br

Eliane Ribeiro Andrade: Professora da Universidade Federal do Estado do Rio de Janeiro - UNIRIO

E-mail: elianeribeirounirio@gmail.com 